\title{
EL ENSAYO EN LA GENERACIÓN URUGUAYA DEL CENTENARIO
}

\author{
Sebastián Miras \\ (Universidad de Alicante)
}

\begin{abstract}
A lo largo de las páginas que siguen intentaremos presentar a una serie de escritores y algunas de las ideas que propusieron en el contexto de lo que se Ilamó en Uruguay la generación del Centenario; artistas cuya labor prosperó en la vecindad de 1930, año en que se conmemoraba el significativo aniversario de la jura de la Constitución de 1830. Me centraré en la figura que fuera animador del grupo «Teseo», Eduardo Dieste, grupo en torno al cual se reunieron una serie de ensayistas, pero también narradores, pintores, escultores, poetas, dramaturgos, etc. Creo que va a ser posible, mediante la presentación de la revista Boletín de Teseo y algunas de las contribuciones más significativas que ocuparon sus páginas, referirse a varias de las cuestiones sugeridas en las líneas temáticas del congreso «Modernidades Excéntricas: Ensayo y redes intelectuales en la modernidad hispánica». Primeramente por considerar la situación de unos intelectuales en la que interviene necesariamente la difusión más allá de las fronteras del propio país: la andadura de muchos de los integrantes del grupo, pero por encima de todo la del propio Dieste, está signada por un desplazamiento constante que resultó en una actividad diversa y profusa en distintas ciudades americanas y europeas. Seguidamente, porque los mecanismos mediante los cuales tiene lugar la difusión de su labor creadora suponen la trabazón de un conjunto de proyectos e intercambios — editoriales, tertulias, premios, exposicionesque amplifican esa tarea. Y por último, ya que esa estructura necesita, en orden de sostener su ramificación, de la participación de ciertas instituciones, empezando por la propia Asociación Teseo y la cátedra que en torno a ella ejerció Dieste, al que Carlos Real de Azúa, historiador y ensayista uruguayo, calificara precisamente así: de «institucional». Dice acerca de Dieste en su Antología
\end{abstract}


del Ensayo Uruguayo Contemporáneo: «ejerció entre nosotros uno de los pocos magisterios vivos que por aquel tiempo operaron y que tendió, por obra de fervorosos discípulos, a organizarse casi institucionalmente» [1964: 142].

\section{El modernismo en la generación del Centenario}

La generación uruguaya d el Centenario es heredera directa, y con esto quiero más que apuntar al hecho obvio de que sucede a la generación del 900 — donde se agrupan nombres tal vez de los más importantes en las letras uruguayas como Carlos Vaz Ferreira, Enrique Rodó, Julio Herrera y Reissig, Delmira Agustini, Horacio Quiroga o Carlos Reyles-, a que es una generación que prolonga la enseñanza de sus antecesores; siendo el modernismo la corriente que afecta predominantemente a la generación del 900. Debe señalarse que la obra que se suele considerar inaugural del modernismo uruguayo pertenece a Carlos Reyles, narrador y, más importante para este trabajo, un ensayista bastante sobresaliente; y que no es en poesía donde se manifiesta sino en su novela Beba, del año 1894, a la que sigue de cerca la tarea de la Revista Nacional de Literatura y Ciencias Sociales, de 1895, impulsada entre otros por José Enrique Rodó, en la que fundamentalmente se recogían producciones modernistas llegadas de otros puntos de América.

Un modernismo algo sui géneris, si se quiere, que enseñó múltiples facetas: desde el vitalismo espiritualista de Rodó y Vaz Ferreira, la dirección más materialista que adoptaron Figari y Reyles, hasta la corriente anarquista y socialista —-modalidad propia del modernismo uruguayo, según Pereda Valdés [1960: 214]— dentro de la cual destaca el nombre de Emilio Frugoni, y al que acompañan Ángel Falco y Álvaro Armando Vasseur como exponentes de la poesía social. Un modernismo de aparición tardía, pero precisamente a consecuencia de ello, con efectos que se prolongaron hasta bien entrada la década del 30. El alcance de haber poseído ciertas características propias puede medirse en la envoltura que tendió sobre el período de la vanguardia histórica, neutralizando parcialmente la entrada de los ismos — ciertamente Uruguay no fue tierra fértil para las vanguardias-, y trasladando la atención hacia la creación de una voz propia del continente. Esto es, claro, una finalidad del modernismo comprendida ya desde Darío; pero en Uruguay, al no haberse experimentado con plenitud la primera de las fases del modernismo — quiero decir, de la evasión, el exotismo y la prodigalidad sonora-, se accede directamente a la segunda de sus fases, en la que 
según diagnosticara Max Henríquez Ureña, existe «el ansia de lograr una expresión genuinamente americana» [1962: 33]. Se acompaña entonces la evolución continental del modernismo, pero, y aquí esté tal vez la peculiaridad, en el contexto uruguayo no hay tradición posible de donde recuperar algunas formas que moldeen, que den una pista, de cuál es el contorno de esa voz propia. Por tanto, aunque coincida la marcha hacia adelante que Ricardo Gullón adjudicara a los movimientos indigenistas, no es posible cumplir con la otra cara de la tendencia que era la de buscar unas raíces propias configuradoras de una identidad. Y al mismo tiempo, como decía, se descartan los ismos, con una excepción destacada que fue el nativismo, o «gauchismo cósmico», como lo bautizara uno de los promotores de esa corriente, el poeta Pedro Leandro Ipuche. Un movimiento, en conclusión, que tuvo manifestaciones rivales en tanto oscilara hacia un tímido juego vanguardista o hacia la expresión local auténtica que se pretendía ubicar, claro, en el medio rural.

\section{La sinceridad literaria}

Un crítico uruguayo, Jorge Albistur, concediendo tal vez una potencia excesiva a las propuestas modernistas de la primera etapa en tierras orientales, describe el movimiento que antes sugerimos:

La generación uruguaya de 1920 — promoción sería término más propio- acompaña el regreso a lo americano que siguió al modernismo en todo el continente. Después de las actitudes evasivas hasta la enajenación, y del derroche sonoro y cromático, por todas partes empezó a oírse la invitación a perseguir «el alma de las cosas» y escuchar «la voz del paisaje». El eje de una nueva postura estética, aunque hubo en ella elementos que la hacen mucho más compleja, fue una vuelta a lo telúrico [Albistur 1992: 1003].

Es también este crítico quien lúcidamente propone que, al menos para el caso de Emilio Oribe, poeta y ensayista perteneciente a la generación que nos ocupa, el rechazo hacia los ismos provino de frecuentar la obra de Paul Valéry, su inteligencia, claridad y disciplina. Oribe propone en su todavía inédito La espuma de la eternidad que su ubicación frente a las vanguardias, incluso frente a los planteamientos ejecutados en Uruguay, fue de rechazo [Albistur 1992: 1008]. Y, ciertamente, esa persecución de la inteligencia aparece en Oribe de forma destacada; una persecución expuesta reflexivamente en las obras dedicadas a formular una teoría estética —obras también ensayísticas, debería agregarse—, en las que, de acuerdo al filósofo Rubén Tani, «desarrolla el tema de la creación, 
de la imaginación, de la poesía y la inteligencia, sobre la estética actual y romántica» [2013: 63]. Pero me interesa apuntar que la obra y teoría estética de Valéry ejercen una poderosa influencia no solo en Oribe, sino también en Eduardo Dieste: ambos inspiran parte de su labor en la perseverante intuición de Valéry.

Estableceremos un nexo entre estos autores a partir de un detalle menor, anecdótico, que traza una conexión entre Valéry y el que fuera uno de los principios rectores de la actividad intelectual no solo de la generación del Centenario, sino de la anterior, la del 900, y también de la generación crítica, la del 45. Me refiero a la sinceridad literaria. En un pasaje de los Cuadernos de Valéry, esas anotaciones a las que dedicó varias décadas, se refiere a la hora en que trabajaba en esos cuadernos, que era muy temprano en la mañana, alrededor de las cinco. Hay dos motivos que le causan satisfacción por dedicarse a esa labor y en ese horario. La primera es que le parece excelente que después de estar trabajando de cinco a ocho, a nueve de la mañana, tener tanto día por delante para comportarse como un estúpido; la otra es que esa hora es la de ser lo más auténtico posible —añado que también Rubén Darío, en tanto adalid del modernismo, reclamó la sinceridad literaria como un mérito para su obra; tal vez el mayor de sus méritos si atendemos a un pasaje de Historia de mis libros, donde afirma: «Y el mérito de mi obra, si alguno tiene, es el de una gran sinceridad, el de haber abierto de par en par las puertas y ventanas de mi castillo interior para enseñar a mis hermanos el habitáculo de mis más íntimas ideas y de mis más caros sueños» (1916 : 43). Explicaré en los párrafos siguientes cuál es la modalidad de esta sinceridad literaria para el caso de los autores antes mencionadas, pero haciéndolo extensivo, como apunté arriba, a las tres generaciones que ocupan la primera mitad del siglo XX en Uruguay.

La idea que se pretende transmitir aquí es que ciertas direcciones en que se desplegó la actividad del pensamiento en una cultura algo marginal como la uruguaya —un pensamiento literario, estético y, si se quiere, filosófico— siguen un núcleo temático definido por Carlos Real de Azúa como «deontología de la cultura», es decir, en los que se atiende con firmeza a los deberes y responsabilidades de aquellos que examinan desde unos ideales estéticos las postulaciones intelectuales del ambiente que los rodea: 
de una nación, de una sociedad, sin que las bases culturales propias de ella sean sólidamente establecidas. Y esta urgente correlación Ileva, a su vez, a otros temas de esta deontología de la cultura y de sus hombres: el debate entre el valor y la conveniencia de las influencias modeladoras; el de los límites, el valor, la impronta, la crisis de la educación; el de cuál es la medida saludable de una relación entre creación y consumo de cultura [Real de Azúa 1964: 50].

Claro que este rasgo por sí sólo no instruye en absoluto acerca del posible contenido que pueda proyectar un grupo de escritores o una generación, pero sí da cuenta, y este punto lo expresa, aunque parcialmente, Fernando Aínsa, del puente que supone la generación del centenario entre la del 900, y el intelectual comprometido del 45:

\footnotetext{
En el comportamiento disidente, cuando no abiertamente provocador, de dandis y bohemios se adivinan los indicios de lo que será la figura del intelectual uruguayo contemporáneo que emerge en los años veinte con el enraizado americanismo literario y, sobre todo, en los treinta, cuando la lucha, primero contra la dictadura de Gabriel Terra y luego contra el fascismo y el nazismo dramáticamente vivido en la Guerra Civil Española, conducen a otras urgencias y compromisos [2002: 55].
}

Pero más diría que esa voluntad diferenciadora se va a manifestar, filtrándose a través de diferentes tendencias que entonces predominan — una anarquía espiritual, mezclada con voluntad de poder nietzscheana y un individualismo que incluye trazas de carácter social y aun cívico-, en la sinceridad, en la comprensión de esa tarea deontológica de la cultura que va a hacer que durante este período vayan juntas las ambiciones estéticas junto con las éticas. Y si bien es cierto que esta mezcla ha sido señalada como uno de los rasgos del ensayo en su conjunto, creo que es especialmente definitorio para la situación histórica y social de América Latina y de Uruguay en concreto. Es tal vez el tránsito que sugiere Francisco Contreras, un poeta y ensayista chileno de la época, en el prólogo a Romances de hoy: «si el simbolismo quiso ser la sinceridad por la libertad, el arte de hoy tiende a ser libertad por la sinceridad» [citado en Llambias de Azevedo, 1950: 175].

\section{El Boletín de Teseo}

Existen con seguridad varios motivos que pueden explicar que el afán por encontrar una expresión particular, sea de la patria, de la región o del continente, tenga en la sinceridad uno de sus atributos. Una explicación de esta cualidad, como decíamos, parte específicamente de algunas posturas 
intelectuales que proclamaban el individualismo como valor; pero algo quizás mucho más concreto fue el carácter autodidacta de las generaciones literarias y artísticas que nos ocupan. Esto puede constatarse en la muchas veces mentada ausencia de centros rectores: la cátedra de conferencias de Carlos Vaz Ferreira en la Universidad de la República es de los escasos ejemplos que existen de instrucción académica. El lugar elegido como sustituto para oficiar las charlas o debates acerca de materias literarias o científicas fueron los cenáculos, los cafés. Como fue de relevante la Librería Barreiro para la generación del 900, o para la del 45 el Sportman, el Metro o el Sorocabana, para la generación del Centenario lo fueron fundamentalmente el Polo Bamba y el Tupí Nambá.

En este último se reunieron el 14 de julio de 1923 un total de catorce pintores, poetas y ensayistas para sentar las bases de lo que sería el Boletín de Teseo, según consta en el primer número de la revista, que aparece algo más de un mes después. Ese primer número consiste apenas del «Acta Fundamental» de la Asociación, un «Registro General» de posibles integrantes, que dejando de lado a los «Iniciadores», se trata básicamente de una nómina que incluía las figuras más destacadas de la creación contemporánea. Como dijimos antes, la Asociación Teseo tuvo vocación de incorporar en sus páginas a todas las artes, como lo muestran las categorías en que se divide la lista: poesía, novela, crónica, teatro, pintura, música, arquitectura, teatro, escultura, cerámica, grabado; pero la primera de esas categorías es el ensayo. Teniendo en cuenta los objetivos de este trabajo, sería necesario destacar algunos de los ensayos que consideramos más relevantes de esta revista, que contó con apenas diez números entre el inicial de 1923 hasta el último de 1925, para más adelante señalar algunas de las ideas estéticas del que fuera su director, Eduardo Dieste.

El primer número del Boletín de Teseo se limita prácticamente a exponer su programa. En esa declaración de intenciones se explica el motivo del símbolo elegido para la revista. La justificación que se da a la preferencia por el héroe griego recuerda al procedimiento que Valéry reservaba para la creación de una obra de arte, que no era en verdad tal creación sino una construcción planificada, analítica y calculada. La revista argumenta que en la figura elegida «se armonizan la belleza de la forma y su construcción rigurosa, la claridad, la gracia, lo ideal y lo humano» [1923a: 1]. Esto se sintetiza a continuación: "Teseo", pues, significa, y nada más: Razón, Belleza y Realidad». Avanzando el programa se discute otra de las cuestiones introducidas antes, la tensión entre la voz propia y la influencia extranjera. Teseo se inclina por el universalismo, sin descartar la articulación de una voz que exprese lo propio regional. Existen, sin embargo, dos dificultades que allí se explicitan: 
primero, que esa expresión no tiene aún una forma definida; se habla de la necesidad de construirla, pero no se sabe cómo se expresa esa identidad nacional; dice: «aún participando de la idea de que la personalidad nacional debe despertarse, hacerse por todos los medios» [Dieste 1923a: 1]. Ese «hacerse» está demandando precisamente una construcción. El segundo obstáculo es uno de elección; debe evitarse la caída en las particularidades ya que son «morosas, arbitrarias y estrechas».

Sin buscar el desprestigio de lo particular de una región, que en el Río de la Plata se reconoció como la expresión del medio rural, existe si se quiere una preocupación por incorporar las regiones interiores del país a la realidad de la capital. Sirvan dos ensayos, o artículos que aparecen en los primeros números. El primero es del propio Eduardo Dieste, titulado «Ley de población», donde reflexiona acerca de la necesidad de desarrollar el proyecto del entonces Ministro de Obras Públicas, que pretendía modificar, diversificar la industria nacional, y esto mediante el aumento de la población y de la tierra para favorecer la industria agrícola, y no sostenerla únicamente como bufé del ganado. Dieste afirma la necesidad de poblar el país para crear una verdadera cultura nacional; dice: «las muchas gentes y no la voluntad de los hombres de Estado hacen la riqueza y el brillo de las naciones» (1923b: 6). El otro ensayo, que en cierto sentido complementa lo expresado por Dieste, es uno de Justino Zavala Muniz titulado «Verdaderas imágenes del país», una crónica de la situación de abandono en que se encuentra el interior de Uruguay, al menos de algunos pequeños pueblos del interior que se hallan sometidos, dice, a la miseria y el vicio. Zavala Muniz cuenta la visita a uno de estos pequeños pueblos, Ferrer, relegado a una situación de verdadero desamparo, y descubre allí una renuncia a cualquier mejoramiento o dignidad humana. Es un Ilamado de socorro para cambiar la condición de estas poblaciones, consecuencia en parte de lo reclamado por Dieste, la ausencia de «cultura», o infraestructuras, o industria, en el interior del país. Sirva de muestra este pasaje para estimar más que el extrañamiento, la desolación con que Zavala Muniz contempla el paisaje humano que ofrece Ferrer:

\footnotetext{
¿Acaso no es digno llamar la atención de los hombres ciudadanos, el estado de estos pueblos perdidos en los campos, donde rigen la holgazanería, el vicio y la miseria? ¿No se encontrará modo de hacer trabajar a todos estos hombres para interesarles en la vida, para salud de la raza y bien del país? $[\ldots]$ De regreso [...], pensamos en lo que debe hacerse de todos aquellos hombres que se quedaron en Ferrer, indiferentes al Bien y al Mal, aguardando como Lázaro, la hora de quedar tendidos para siempre en un rincón del rancho miserable [1923: 4].
} 
Sin embargo, la discusión de mayor alcance, puesto que en alguna medida comprende la situación de marginalidad expuesta recién, es la de la promoción y también el impulso de un arte americano. Ante la dificultad de proclamar la existencia de unos valores y expresión propias, la salida es la actitud americanista, como sugiere Alberto Zum Felde en «Principios de una cultura americana», aparecido en el número 7. El historiador y ensayista, autor de Proceso histórico del Uruguay y Proceso intelectual del Uruguay, reconoce que la identidad continental ya no se corresponde con la española, como tampoco lo hace, a pesar de la potente influencia cultural, con la francesa; que se ha dejado atrás la posibilidad de reconocerse como tales si bien todavía no se ha constituido una identidad que la suplante. Es por eso que la solución es ampararse, y activamente indagar, en la expresión continental:

\footnotetext{
es indudable que nuestra personalidad más próxima en lo futuro, es decir, la primera faz de nuestra personalidad americana, ha de producirse por la fusión de dos elementos: el histórico y el cultural [...] No podemos apartarnos de esos elementos positivos, ni prescindir de ese «hecho histórico», al intentar la inducción de nuestra personalidad en agraz [Zum Felde 1924: 10].
}

En este sentido, aparece en el número 4 el artículo «Arte americano», de Juan Santos Genovese, en el que se aprecia con claridad la particular situación del uruguayo. Santos Genovese, arquitecto de profesión, invitaba a meditar sobre lo que pudiera servir de estímulo en el abundante arte precolombino, sobre el cual dice, surgen las manifestaciones artísticas más esperanzadoras:

\footnotetext{
Si al enterarnos de ese desconcertante caudal de producción artística precolombina, meditáramos sobre una moderna y lógica utilización de todo lo que nos pueda ofrecer un punto de inspiración, de nueva composición, de estilizaciones desconocidas y audaces tanto en los pequeños como en los grandes temas y que son en realidad modalidades de la aspiración presente, podríamos Ilegar a obtener un arte propio, que es la mayor preocupación actual de todos los países [1924: 2].
}

Si se admite la aparición de un movimiento americanista es porque se ha abandonado la confortable postura de continuar con la repetición de las realizaciones europeas. Pero ahí mismo se sitúa el inconveniente: ipueden esas supuestas fuentes propias de lo americano crear no ya la cultura de una región cuya situación política, de producción y social se ha modificado, sino de una a la que esas fuentes le son en gran parte extrañas? 
De todas formas, Uruguay sí participó de ese movimiento renovador americanista, con la obra pictórica de Figari o Torres García, la música de Eduardo Fabini, o la poesía del movimiento «neo-nacionalista», o nativista como lo bautizara Pereda Valdés. No estoy seguro, sin embargo, del alcance de esa pretendida renovación, o de haber existido, si ha prosperado no ya con el significado que pretendían sus autores, sino con algún sentido de búsqueda identitaria.

Juan Filartigas, en un artículo dedicado a Emilio Oribe que aparece en el número 5, afirma que se estaba produciendo entonces un movimiento de renovación, un movimiento serio de modernidad, pero los nombres que cita no son los han perdurado como más representativos de ese movimiento americanista, o nativista. Existía sí la percepción de que la literatura estaba atravesando un período revolucionario, de que se aspiraba a decir cosas nuevas en formas nuevas, pero esa iniciativa se emprendió evitando la tradición — sea cual sea el significado que se le quiera atribuir: naturalismo, realismo-, y al mismo tiempo criticando movimientos de vanguardia como el ultraísmo. De hecho, el reconocimiento que Filartigas hace a Oribe es el de estar consiguiendo una realización nueva sin la necesidad de emular la práctica de los ismos. Está muy arraigada la idea de que las revoluciones artísticas se suceden, pasando a ser las anteriores retardatarias, un obstáculo para el advenimiento de formas nuevas.

Queda pendiente todavía glosar el significado y la finalidad, de existir alguna, que se encuentra detrás de la búsqueda de esa expresión propia. Creo que existen algunas referencias concretas en otro ensayo de Zabala Muniz, que aparece en el número 6, titulado «Fomento de la cultura artística del pueblo», y remite en gran medida a lo sugerido por Dieste acerca de la «Ley de población». Lo que discute Zavala en primer término — hay que precisar que el ensayo fue también un proyecto presentado en la Cámara de Representantes_ es la protección que debe proporcionar el Estado a sus artistas — partiendo de una idea cuanto menos engañosa, y es la de pretender que el artista sería mucho más prolífico de no haber padecido ciertas estrecheces-, y no permitir así que caigan en la miseria individuos que tendrían mucho que aportar a esa función positiva que se pretende del arte. Porque hay que concretar que la influencia que hay detrás aquí es la de Jean-Marie Guyau; lo que se busca con este proyecto, tal como sucedía con la repoblación del interior del país, es crear una sociedad, un sentimiento de nación.

La cuestión de fijar, o insinuar, los valores estéticos presentes entonces en el país era problemática, y no solo por la complejidad de la tarea, sino porque se entendía que las epopeyas 
que habían servido para construir el sentimiento de nación en la época de la independencia ya no tenían efecto en la sociedad del «Centenario», una sociedad que se esfuerza por renovar los valores de aquella otra y de renovar su impulso, pero que está ante un entramado social, económico y político completamente distinto y por tanto es forzosa la reinvención del relato nacional.

En la sección de «Crítica de arte» del número 6 del Boletín, Eduardo Dieste alude al mismo conflicto en términos similares. El compromiso con un arte nacional se justifica por lo negativo que sería haber conseguido la independencia para pasar a ser una «colonial espiritual de todo el mundo»; no es forzoso, sin embargo, pretender que esas manifestaciones enseñen algo enteramente novedoso, lo relevante es su contribución al desarrollo de la «personalidad nacional». Allí se sitúa la función del arte nacional: «es necesario un Arte nacional como función. La necesario aspiración de un arte diferenciado ya tendrá cumplimiento a su hora. Lo primero es ser y lo que sigue al ser: el obrar» [1924: 14].

Quisiera, para finalizar, realizar algunos apuntes referidos a la orientación más dirigida hacia el pensamiento teórico, estético, que fue ofrecido por la figura rectora del Boletín de Teseo, Eduardo Dieste. La intención del bosquejo que modela el último apartado es la de sugerir la unión que existe entre las modalidades éticas y estéticas del ensayo uruguayo en la generación del 30, tal como se planteó al comienzo de este trabajo.

\section{La base folclórica de Eduardo Dieste}

Algo más conocido, especialmente en tierras europeas, es su hermano, Rafael Dieste, narrador, dramaturgo y ensayista, que nació en Rianjo, donde se había instalado la familia luego de volver de Uruguay hacía ya algunos años. Tenían allí una finca familiar y algunas propiedades, y se habían asentado tras la muerte del abuelo paterno. Eduardo era 17 años mayor que Rafael. Había nacido en Rocha, un provincia costera del este uruguayo, limítrofe con Brasil. A esa edad, a los 17 años, ingresa en el Seminario Conciliar de Santiago de Compostela. Al finalizar los estudios renuncia al sacerdocio y estudia Filosofía y Letras. Profundiza entonces su amistad con Castelao, a quien conocía desde sus años en Rianjo, donde fundan, con algunas personas más, El barbero municipal, una revista que aparece desde 1910 hasta 1914. Sin embargo, Dieste permanece poco tiempo en la revista, ya que al año siguiente decide emigrar a causa de algunos enfrentamientos con caciques de la zona. 
El barbero municipal tenía una línea muy crítica con ciertas políticas caciquiles que tenían lugar en la Galicia de entonces. Dieste recibe amenazas como consecuencia de sus denuncias en $E$ l barbero y decide emigrar a Uruguay. Allí se convierte en director de Instituto en una provincia de Uruguay; hace algunas traducciones, traduce a Shakespeare y a Chesterton, entre otros. A las pocos años entra como diputado en la Cámara de Representantes, y es en 1923 que funda, como se dijo antes, el grupo «Teseo». Unos pocos años más tarde es destinado como diplomático a Londres, luego a Bilbao, Cádiz, Madrid, donde impulsa en 1935 la revista P.A.N. (Poetas Andantes y Navegantes). Debido a un desacuerdo con el Gobierno uruguayo, que había roto relaciones con la República, abandona su cargo en Madrid y vuelve a Montevideo. Nuevas funciones diplomáticas lo harán trasladarse, como cónsul, a San Francisco, Nueva York, y finalmente a Santiago de Chile, donde muere en 1954.

Voy a referirme fundamentalmente a algunos aspectos de la teoría literaria que presenta Dieste en uno de sus libros, colección de ensayos en verdad, que se titula Teseo. Los problemas literarios. El libro se publica en 1938, en una pequeña editorial y Asociación que funda a su vuelta de España, su segunda vuelta, y llamó Reuniones de Estudio, que no tuvo tanta resonancia local como la que tuvo Teseo. Lo primero que hay que señalar es que la prosa de Dieste es bastante oscura, el armado de las ideas es un tanto confuso, y en verdad nunca se termina de definir el sentido de muchos de los términos que utiliza. A pesar de todo y para ser justos, era una modalidad bastante acorde a la época. Muchos escritos de Vaz Ferreira se presentan así, también de Figari, del propio Emilio Oribe, etc. Carlos Real de Azúa informa de algunas de las corrientes que influyeron en su desarrollo intelectual: «"ontologista", "esencialista", "metafísico", ciertos sustantivos que vuelven reiteradamente a sus juicios: unidad, cualidad, número» [1964: 143]; este es, a gran escala, el plano que conforma una teoría estética que dirige su atención a la experiencia del artífice literario. Un pasaje de Los problemas literarios pueden dar cuenta de estos «sustantivos» que auxilian las reflexiones de Dieste: el ensayista enfrenta la imaginación a la medida en busca de una respuesta a la cuestión de cuál de estos conceptos despliega más ajustadamente los avatares del hombre:

\footnotetext{
¿Basta el medio de la imaginación para dar la resonancia del alma en el mundo? ¿Es, por el contrario, la medida lo que hace una tragedia griega más grave y menos lacerante que una drama moderno? ¿Es que el número circunda en una esfera divina el misterio de la existencia, y la sola imaginación lo deshace en el contrasentido de las aflicciones humanas? [1938: 29].
} 
Pero Dieste no ubica la solución en ninguna de las dos categorías, la idea y la imagen deben estrechar sus potencias ya no confundiéndose, sino favoreciendo el momento artístico en un vaivén que otorgue a cada una, bajo la tutela de la imaginación, la oportunidad de prodigarse:

\footnotetext{
Vemos primero la imagen de los ojos, y no nos contenta; y de sensible la llevamos a inteligible, y no nos contenta; en este vaivén de angustia viene en auxilio [...] la imagen de la imaginación; entonces ajustamos los ritmos de corporeidad y accidentes, de significado ideal e ímpetus cordiales; una imagen trae otra en vuelo, el paso de lo sensible a lo inteligible, la acción especulativa, estética, es cada vez más firme y exenta de sus riesgos, que son: morir en la idea o yacer en la imagen [1938: 43].
}

Dieste entiende que la norma no puede gobernar de ningún modo el arte, por tanto el clasicismo que podría entenderse a partir de su obra, debe necesariamente contener elementos nuevos, con un empuje romántico, elementos latinos, una tendencia platonizante, por ejemplo cuando explica que todos tenemos la sensación, al escuchar un buen poema, de conocerlo ya desde antes. Se matiza la importancia de la originalidad. Reprocha suavemente el autodidactismo, aunque la censura más grande sea tal vez la que destina al extremo opuesto, al academicismo — ampliaré esto en un momento-, si bien existen trazas de aquél en la idea de que solo puede explicar la ley de un arte quien lo practica. Esto se difumina algo al pronunciar también que es no solo el que lo practica, sino quien lo discute directamente con sus creadores, por lo que es un noción un tanto débil.

Es necesario destacar la distinción de Dieste entre el saber folclórico y el saber académico. El ensayista no llega a hacer de esto un dualismo justamente debido a que la base del conocimiento es la primera, la folclórica, que es la que más se somete a la realidad. Como vimos hace un momento, Dieste entiende la imaginación como mediador en un paso que se podría entender como de lo sensible a lo inteligible, remedio que socorre ante la insatisfacción de experimentamos ante la imagen y la pura idea. El objetivo es la influencia recíproca que debe producirse entre la imagen y la idea, consiguiendo así la «difícil facilidad». Este es según Dieste el signo más claro de acierto, el de la simplicidad: «la corriente folklórica del conocimiento [...] se determina por imperativo vital, y se transmite por vía de amor; se produce y se reproduce orgánicamente por linajes» [Dieste 1938: 79]. El saber folclórico parece adaptarse más a esa pretendida simplicidad ya que obedece a la realidad, obtiene verdades integrales y sus saberes ingresan por los ojos del cuerpo y los del alma. El saber académico, por el contrario, se desvincula pronto del principio de realidad y se corrompe al 
reproducir insistentemente teorías abstractas. Hay un punto que parecería contradecir el rechazo de las normas para la creación artística, cuando dice que la vía más fiable de creación se encuentra en los linajes, en la tradición, y que en el dogma que necesariamente la acompaña siempre hay saber folclórico; sin embargo advierte que no es el folclore repetido por los académicos sino, puntualiza, un folclore auténtico que transmite la realidad del «verso» y la realidad divina. Respecto a esto último, algunos críticos encuentran la influencia de un catolicismo intelectual al estilo de Jacques Maritain.

Pero el organicismo que encierra la reflexión de Dieste necesita también un momento de reflexión posterior al saber intuido. Al igual que ocurre con la pareja entre imagen e idea, también es imperiosa la existencia de una instancia adicional que armonice los conocimientos que difunde el saber popular, folclórico. Ahora la idea, la medida, parece implicar una suerte de intercambio que el organismo mantiene con la realidad exterior al creador:

\footnotetext{
En este supuesto y no hay otro mejor, de que el alma del artista venga a ser fertilizada por las aguas del saber popular y nutrida con elementos de experiencia personal, más la observada ajena, una cosa falta que no le viene dada desde fuera; y es la armonía de lo aprehendido [...] Cuando el organismo del cuerpo no comercia con el exterior, antes de morir se alimenta de sí mismo; hay una vida celular después de la muerte somática. Si el espíritu vive de sola reflexión egoísta dará en autofagia y muerte [Dieste 1938: 82, 83].
}

\section{Conclusiones}

Nos proponemos plasmar una última influencia, u otra declaración de intenciones, donde convergen muchas de las cuestiones que se han intentado esbozar aquí. Y es que en el último número del Boletín de Teseo, cerrando el ejemplar, aparece el testamento artístico de Auguste Rodin, esa carta que dedica a los más jóvenes. Dentro de las muchas recomendaciones que da Rodin, hay una que enlaza directamente con lo dicho aquí: el respeto a la tradición debe hacerse aprovechando su pródiga sinceridad:

\footnotetext{
Respetuosos de la tradición, sabed ver lo que ella encierra de eternamente fecundo; el amor a la naturaleza y la sinceridad. Estas son las dos grandes pasiones de los genios. Todos han adorado la naturaleza y jamás nos han mentido. También la tradición os da la clave gracias a la cual os podréis librar de la rutina. Es también la tradición que os recomienda interroga sin cesar la realidad y os prohíbe someteros ciegamente a ningún maestro [Rodin 1925: 41].
} 
Sin duda sería provechosa la elaboración de una historia del concepto de sinceridad a los efectos de la propuesta hecha en estas páginas. Una investigación acerca del «campo de experiencia» y el «horizonte de expectativas» de dicho concepto — presente en Ángel Rama y Carlos Vaz Ferreira, entre otros-, podría ser de gran ayuda para la interpretación de lo que estas generaciones se propusieron transmitir, partiendo, claro, de la presunción de que, dejando de lado las inevitables diferencias, existe un proyecto común a estos autores directamente vinculado a la construcción identitaria nacional y latinoamericana.

Sin embargo, la inclusión de «Mi testamento» en el que sería el último número del Boletín de Teseo permite trazar un vínculo con el «Acta fundamental», el programa que aparece en el primer número. Allí se proclamaba el universalismo como principio rector, afirmando al mismo tiempo que la persecución de ese principio no se opone la necesidad del «despertar de una personalidad nacional». El testamento de Rodin, único escrito de autor extranjero que figura en el Boletín, viene a ratificar el universalismo guiado por la sinceridad literaria propuesto al iniciarse el recorrido de la publicación. Y tal vez, se haga, prolongando un magisterio, de un modo similar al que años atrás propusiera Vaz Ferreira, cuando razonaba hasta qué punto debe la sinceridad conducir al escritor:

[explicar] lo que es a fondo esa tarea y cómo y en qué grado debe colmarnos, lo que realmente debemos permitirnos escribir, qué grado de adecuación a nuestra razón debe tener, tanto desde el punto de vista de la verdad como del grado de nuestra adhesión, y qué grado de adecuación no solo a nuestra razón sino a toda nuestra personalidad, a nuestros sentimientos y también qué fuerte debe ser la impresión de importancia que nos haga lo que pensamos o lo que proyectamos para que tengamos el derecho de escribir [1963: 377, 378].

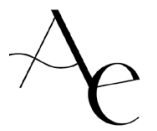




\section{BIBLIOGRAFÍA}

AÍNSA, Fernando: Del canon a la periferia: Encuentros y transgresiones en la literatura uruguaya. Montevideo: Trilce, 2002.

ALBISTUR, Jorge: «Emilio Oribe, o la hoguera hecha estatua», Revista Iberoamericana, LVIII, 160161 (1992), pp. 1001-1013.

ARDAO, Arturo: La filosofía en el Uruguay en el siglo XX. México: FCE, 1956.

CASTILLO, Homero (coord.): Estudios críticos sobre el Modernismo. Madrid: Gredos, 1974.

DARÍO, Rubén: Antología. Poesías. Madrid: Librería de la viuda de G. Pueyo, 1916.

DIESTE, Eduardo: «Acta fundamental», Boletín de Teseo, 1 (25 de agosto de 1923a), pp. 1-2.

DIESTE, Eduardo: «Ley de población», Boletín de Teseo, 2 (20 de septiembre de 1923b), pp. 6-8.

DIESTE, Eduardo: «Discusión estética y ejemplos. 1914-1924», Boletín de Teseo, 6 (10 de mayo de 1924), pp. 14-15.

DIESTE, Eduardo: Teseo. Los problemas literarios, Montevideo: Reuniones de Estudio, 1938.

EARLE, Peter: "El ensayo hispanoamericano, del Modernismo a la Modernidad", Revista Iberoamericana, 118-119 (Enero-Junio 1982), pp. 47-57.

EARLE, Peter, y MEAD, Robert: Historia del ensayo hispanoamericano. México: Ediciones de Andrea, 1973.

FILARTIGAS, Juan: «Emilio Oribe», Boletín de Teseo, 5 (14 de abril de 1924), p. 5.

GULLÓN, Ricardo: Direcciones del modernismo. Madrid: Alianza, 1990.

HENRÍQUeZ UREÑA, Max: Breve historia del modernismo, México D.F.: Fondo de Cultura Económica, 1962.

JIMÉNEZ, Juan Ramón: El modernismo. Madrid: Visor, 2010.

LLAMBIAS DE AZEVEDO, Alfonso: «El modernismo», Anales de la Universidad de Montevideo, 166 (1950), pp. 163-189.

MONGUIÓ, Luis: «De la problemática del modernismo: La crítica y el "cosmopolitismo"», Revista Iberoamericana, 53 (Enero-Junio 1962), pp. 75-86.

PEREDA VALDÉS, Ildefonso: «El modernismo en el Uruguay», Revista Letras, núm. 11 (1960), pp. 204-214. 
REAL DE AZÚA, Carlos: Antología del Ensayo Uruguayo Contemporáneo. Montevideo: Publicaciones de la Universidad de la República, 1964.

RODIN, Auguste: «Testamento», Boletín de Teseo, 10 (28 de febrero de 1925), p. 41.

SALINAS, Pedro: «El modernismo», Letras, 2 (1965), pp. 21-24.

SANTOS GENOVESE, Juan: «Acta fundamental», Boletín de Teseo, 4 (14 de febrero de 1924), pp. 2-3.

TANI, Rubén: Etapas del pensamiento en Uruguay, 1910-1960. Montevideo: Casa editorial HUM, 2013.

VALÉRY, Paul: Cuadernos (1894-1945). Barcelona: Galaxia Gutenberg, 2007.

VAZ FERREIRA, Carlos: Inéditos, tomo XX. Montevideo: Ed. Cámara de Representantes del Uruguay, 1963.

ZAVALA MUNIZ, Justino: «Verdaderas imágenes del país», Boletín de Teseo, 3 (12 de octubre de 1923), pp. 1-4.

ZAVALA MUNIZ, Justino: «Fomento de la cultura artística del pueblo», Boletín de Teseo, 6 (10 de mayo de 1924), pp. 10-14.

ZUM FELDE, Alberto: «Principios de una cultura americana», Boletín de Teseo, 7 (14 de julio de 1924), pp. 4-10. 